\title{
Relevant Exploration On The Application Of Chinese Traditional Culture Elements In The Graphic Design
}

\author{
Yaxiang Ding \\ College of Art and Design, Jiangsu Institute of Commerce, Nanjing, 211168, China
}

\begin{abstract}
Keywords: Chinese traditional culture, Graphic design, Culture elements, Relevant exploration, Application
\end{abstract}

Abstract. Due to the society`s development, the economy and culture also enjoy constant
development, and the whole society now become more and more multi-polarized. China`s a civilized
ancient country with a history more than 5000 years, while the traditional culture is a collection of
many elements, it contained many excellent elements, these elements are not only the soul of out
nation, but also the representation of China`s long-standing history. If we integrate the fine
traditional culture elements into graphic design, not only the quality can be improved, the fine
traditional culture can also be promoted. In the multi-culture age,many culture intermingle with each
other. The graphic design is an important mean and approach to promote the traditional Chinese
culture, this can also very well prove the unique charm and existence value of the traditional culture.

\section{Introduction}

The traditional Chinese culture has rich content and long history, the culture deposits is also very profound. The traditional culture element inject new vitality to the graphic design. It also provides rich creative themes and fine art inspiration. Integrating traditional Chinese elements with graphic design, it can not only improve the visibility and gold content of the product, but also enhance the culture literacy and economy value of the products, this also make great contribution to advocating the Chinese traditional culture.

\section{The Character of the Chinese traditional culture elements}

Because China is a large nation with many different ethnic group, so the traditional Chinese culture also have many different forms,and it also develop into a multi-polarized direction, the distinctive national culture of the minority ethnic group added much new strength and vitality to the traditional Chinese culture. The manifestation of the traditional Chinese culture is color, some are dynamic(like the dancing and special festival of the minority group), some are static(like places of historic interest and totem etc. ). The art has compatibility and creativity, and that is what makes it attractive, it has absorb many different culture element, and conducted transformation,that is how the art with special meaning be created. The colorful traditional Chinese culture can be applied into many different art creation and design work(such as the Chinese style,dragon and phoenix totem and Peking opera facial makeup etc. )

These can be called the typical traditional Chinese culture elements, it enjoys very good development in its field, and very popular among the citizen. Thus people can learned that the traditional Chinese culture enjoy a very significant nationality character, and its distinctive characteristic can also be called another feature. Due to the long and profound traditional culture history, the traditional Chinese culture also has special feature, the massage expressed in different culture is also different. But they all share one thing in common,which is it can show the colorful and long-standing culture of a nation. From which we can see that, there are many forms and multi-feature in the traditional Chinese culture, which also reflected the distinctive culture flavour and nationality. 


\section{The basic feature of the graphic design}

Design is a creative activity based on the commercial environment which is different from the art, it is a job or an occupation that purposely done by the designer and the design team. Design could also be the formative activity to create beauty and memorialization. it serve the public, it is based on the general public and commericial business, in order to create commerical and art value, which distinguished design with art.

The graphic design covers both the knowledge and the skills, so it is often misunderstood as the visual communication design, the designer can use multiply ways to endow the words and images with visual thoughts. The graphic designer would sometimes use certain approaches(font layout, visual art and space technology) to make his work perfect.As the products of the commercial society, it is the combination of the technology and art, it is needed to realize the balance between the art design and ideal creation in the commercial society. While it takes constant changes and improvements to finish a design, the designers need to challenge and improve themselves all the time, there is no complete concept. The important factor of the design is the personal experience and feelings, that is also the point to make a design work impressive. It takes many details(the graphics idea must be impressive, the color taste must be impressive, the material texture must be impressive)for a design work to impress the others, combine many factors together effectively, so the designer need to be strictly self-discipline to make his design work impressive.

\section{The current situation of graphic design in China.}

As the world economy has become more and more multi-polarized, the traditional Chinese culture is now attracting more and more attention all over the world. The traditional Chinese culture elements now have been widely applied, which has also brought the traditional Chinese culture s charm onto the world stage. Chinese economic development potential and culture diversity has created great impact and shock to the world, it also has showed China`s strength to the world. People gradually became familiar with "Made in China" "China brand". But there remain many defects in China`s graphic design.

\section{The graphic design lacks of creativity, and it pays attention to the form only}

Although the graphic designer was first developed in the foreign countries, it was introduced to China only after the 1980s. Although it has developed for several decades, but the graphic design in China is still far behind those in the foreign countries, the most important reason is the lack of creativity, and attentions paid only to the form. There are many graphic design is simply the imitation and copy, which couldn`t integrate the traditional Chinese culture into it effectively. And some graphic designer could not control the design concept very well. Which makes it impossible to improve China`s graphic design.

\section{Choose the graphic design material blindly.}

During the graphic design process, many graphic design work has adopted the traditional Chinese culture elements, but not according to the selection principles, it is indiscriminately imitation at all, which makes the work loses its character and style, and it can no longer enjoy any advantages. Although the traditional Chinese culture can facilitate and enrich the graphic design, it doesn `t work for all kinds of work. The graphic design needs the analysis of the modern aesthetic concept,if the designer adds the traditional Chinese culture elements into graphic work blindly, this would not only makes the work less appealing, but also lose the traditional Chinese culture`s value.

\section{The integration of traditional Chinese culture to graphic design}

China has thousands of years` history, which is surely profound, so there must be many different manifestations in the graphic design. The categories of traditional Chinese culture (calligraphy, dragon and phoenix totem, ancient coins,Peking Opera, facial makeup, and traditional painting,etc) is also of various kinds, the things mentioned above are all those with distinctive character and highly representative, so the graphic design needs to change in order to adopt to the time`s changes actively. 
In a more and more multi-polarized world today, the traditional Chinese culture elements now has become more and more attractive.

\section{The application of dragon and phoenix totem in the graphic design}

The dragon and phoenix are the symbol of good luck and power. Ever since ancient time, the dragon and phoenix totem has always represented the highest ruler and highest power in China. As typical traditional Chinese culture, it is mostly applied in the costume. And there are many graphic designs of the costume would apply this culture elements into the costume pattern design, even in some International costume design(such as some famous superstars would wear the costume with Chinese culture elements to attend some grand international events), the most famous cases are the cheongsam with dragon and phoenix pattern and the traditional Chinese garments with traditional dragon pattern. There are many famous jewelry enterprises, Long Feng Xiang jewelry, it is a gold shop with a dragon and phoenix as its trademark. These are all very good examples of integrating the traditional Chinese culture elements with the graphic design.

\section{Traditional calligraphy applied into the graphic design}

As the standard of the Chinese character writing, the calligraphy is a special manifestation and artistic behavior of traditional Chinese culture. The history of calligraphy is as long as the traditional Chinese culture, it has very profound and rich culture deposits. As the manifestation of traditional Chinese culture, it witnessed the development and progress of China`s history development. Chinese characters, which is also called the Chinese words, enjoys wide popularity among people in the culture community, it was invented, adopted and improved by the Han people in ancient times. The appearance of the Chinese words experienced many processes. (the Oracle appeared in 1300BC Shang dynasty,Xiaozhuan in Qin dynasty, and it was named as the "Han Character", "Kaishu"in Tang dynasty), the Han Character lasts for the longest time, it is the only words that inherited from the ancient period, Han Character is also the major official words of most dynasties in Chinese history. So we can say that the calligraphy is most representative among the traditional Chinese culture.

As the society develops, China`s status in the world constantly increases, the traditional Chinese culture has now been known by more and more people, and recognized by the people in the world. It now has been more and more frequently used in the graphic design.Many designer would integrate the traditional Chinese culture with graphic design, which makes the unique character of the traditional Chinese culture well exemplified in the graphic work. The most earthshaking design is the emblem of Beijing 2008 Olympic games, which called the "CHINA SEAL"(it was written by hand, it mainly adsorbed the rich Chinese humanity culture, which includes traditional Chinese calligraphy concept.) it is a design with decidedly Chinese touch, which makes the traditional Chinese culture even more popular in the world.

\section{The application of "Chinese red"}

Chinese people are sure to be familiar with the color red, while the color red is one of the favorites of the Chinese people, it has become the culture totem and spiritual convert of Chinese people. While the Chinese modern history also considered as a red history(Red is the red boat on the South Lake, is the gunfire of Naichang, is the sparks of fire on Jianggang Mountain, is the utter devotion on the mountain and grassland, is the Chinese people`s prosperous life, is the constantly-uprising overall national strength of China.) it has contained everyone`s red memory in China.

While the Chinese red was called the soul of Chinese people, because the red represent the passionate, unity, unremitting self-improvement national quality. The color red absorbed many elements(such as the morning sunrise`s power,the most glamorous sunset glow, the extreme warm of the fire, the most active and thickest part in the blood, Acacia beans means the most delicate emotion, the maple leaf means the most mature late autumn image, etc ) this makes Chinese red the symbol of good luck.

The Chinese red can be found in people`s life anytime and anywhere,people like to render and regulate the atmosphere during the traditional festival with the color red, so the color red was called the representative color of China. Such as the national flag, Chinese tie are all of red color. While adopting red can not only advocated the traditional Chinese culture, it can also be on the top fashion world. As china`s development keeps going forward, China has gradually become connected with the 
world. Many traditional Chinese culture elements have been applied in many sectors in the world, which has show the special culture content and charm that china possess.

\section{Conclusion}

The traditional Chinese culture is the essence and soul of Chinese culture, it is also the wealth of Chinese culture, it has provided very good material for the graphic design, which has integrated the modern and traditional elements together effectively. As the world`s globalization continues, the culture also has developed into a multi-polarized direction. From which we can see that the graphic design also need to keep up with the pace and integrate the traditional Chinese culture element into the graphic design in a rational way. In the globalization of the design, as a graphic designer, we need to try our best to utilize our function and ability, make China`s graphic design good enough to leave a mark in the world, integrate the traditional culture to the modern design, thus to promote the Chinese graphic design to make it reach out to the world, this is the grand and painstaking responsibility as a designer.

\section{References}

[1] Zhang Xiaolan, Dai Xiaoling. Analysis of regional and national culture`s transmission and promotion from the visual aspect[J] Commercial era, 2010 (26).

[2] Qian Xiaolun, Thoughts on the inheritance and application of the traditional culture elements in contemporary display design [J] Art and design (theory),2012(04)

[3] Zhan Weifeng. Analysis of the symbol`s application in the graphic design and its function[J] (Chinese philosophy Society Sciences Edition)2010(04)

[4] Yang Yuping, Yang Mingjun, explore of the network structure in the graphic art design in a tradition way[J] Chinese technology wealth, 2008(07).

[5] Tang Shaojun, Shen Dekun. The application of the traditional Chinese culture elements in the contemporary graphic design[J]. Friends of Art.2008(03)

[6] Wu Xingkuan,Qiuhong Discussion on the application of ethic culture in the contemporary visional communication[J] Journal of South-Central Nationalities University (Humanities and Social Sciences Edition) 2002(01).

[7] Qiao Fanghui Zhang Qilong. Discussion on the meaning of the protection, heritage and exploration of the folk culture from the development of the hundred years old dough modelling village.[A] Academic workshop on "heritage protection and exploration of the contemporary folk culture" 20 anniversary of the foundation of the Shandong folklore society memorial symposium .[C] 2007

[8] Zhou Xiaoo, Zhou Xiaoxin. Explore the local design in tradition[A] "Pine, bamboo and plum-poetic design"-- the Mainland, Taiwan and Hong Kong; traditional Chinese pattern and modern vision design academic workshop symposium [C]2007.

[9] Wu Xiangyong “Globalization”give catalyze the rediscovery of the tradition "Pine, bamboo and plum-- poetic design”--- the Mainland, Taiwan and Hong Kong traditional Chinese pattern and modern vision design academic workshop symposium [C]2004

[10] He Baiyun, Tanaka light and Jin Daiqiang-- the fusion of the modern art graphic design and traditional culture [J] Jiangsu social science 2007. 